\title{
Estratégias Organizacionais na Trajetória da EMPASC
}

\author{
Lucy Woellner dos Santos \\ Elisa Yoshie Ichikawa \\ Cristiano J. Castro de Almeida Cunha
}

\begin{abstract}
REsUMO
Este artigo tem por objetivo identificar e analisar o padrão estratégico da Empresa Catarinense de Pesquisa Agropecuária (EMPASC), no período de sua existência (1975-1990). Metodologicamente este é um trabalho quantiqualitativo. É um estudo de caso longitudinal com perspectiva histórica, buscando compreender o contexto no qual se deu a trajetória da EMPASC. A análise revelou um padrão estratégico de constante crescimento, observado na identificação de indicadores tais como a programação de pesquisa, o quadro de pesquisadores, o número de estações experimentais, publicações e outros. Além desse padrão, três estratégias foram analisadas com maior profundidade, por terem representado momentos relevantes na trajetória da pesquisa agrícola em Santa Catarina no período analisado: o vínculo com a Empresa Brasileira de Pesquisa Agropecuária, a articulação com o Governo do Estado e a parceria com a iniciativa privada.
\end{abstract}

Palavras-chaves: padrão estratégico; estratégias; pesquisa agrícola.

\begin{abstract}
This paper aims to identify and analyze the strategic pattern of the Empresa Catarinense de Pesquisa Agropecuária (EMPASC), during its existence (1975-1990). Methodologically this is a work quantitative and qualitative. It is a longitudinal case study having a historic perspective, trying to comprehend the context in which the EMPASC's trajectory has occurred. The analysis reported a strategic pattern of steady growing, observed in the identification of indicators such as the research programming, the researchers' board, the number of experimental stations, publications and others. Besides this pattern, three strategies were analyzed more deeply, by having represented relevant moments in the trajectory of the agricultural research in Santa Catarina State in the analyzed period: the connection with Empresa Brasileira de Pesquisa Agropecuária, the articulation with the state government and the partnership with the private sector.
\end{abstract}

Key words: strategic pattern; strategies; agricultural research. 


\section{INTRODUÇÃO}

A definição de estratégias organizacionais em entidades públicas possui características diferenciadas daquelas com objetivos estritamente privados. $\mathrm{O}$ fato de possuírem objetivos sociais, de contarem basicamente com recursos provenientes do próprio setor público para a sua manutenção, de terem limitações intrínsecas à natureza de suas atividades para a geração de receitas, e de serem mais suscetíveis às injunções políticas, confere a esses órgãos peculiaridades que se refletem nos seus processos organizacionais, em especial na definição de suas estratégias.

A análise das estratégias adotadas pela Empresa Catarinense de Pesquisa Agropecuária (EMPASC), constitui o objetivo do presente trabalho. O período compreendido por essa análise estende-se de outubro de 1975, data de sua criação pelo Governo do Estado de Santa Catarina, até abril de 1991, quando a EMPASC foi extinta. A sua extinção ocorreu como parte de um programa governamental de reforma administrativa, dando origem à Empresa de Pesquisa Agropecuária e Difusão de Tecnologia (EPAGRI), que passou a coordenar e executar não só as atividades de pesquisa agrícola no Estado, mas também as de extensão rural, pesqueira e apícola.

Embora o período de vida da EMPASC some um total de quinze anos e seis meses (outubro de 1975 a abril de 1991), para efeito da análise a ser realizada no trabalho serão considerados quinze anos de atividade, ou seja, 1975 a 1990.

A justificativa desse estudo se explica por vários motivos: primeiro, pela importância de se analisar toda a trajetória de uma organização, desde a sua criação até a sua extinção; segundo, pela possibilidade de aplicar um modelo de análise que pressupõe uma perspectiva longitudinal, ou seja, o padrão estratégico de Mintzberg (1992); e por fim, pelo pressuposto de que a realidade atual pode ser melhor compreendida a partir da interpretação dos eventos que ocorreram no passado. Como conseqüência dessa escolha, metodologicamente optou-se por uma abordagem de pesquisa histórico-organizacional.

Para atingir o objetivo pretendido, de identificar e analisar as estratégias organizacionais que caracterizaram a atuação da EMPASC nos seus quinze anos de existência, são apresentados, a seguir, os fundamentos teóricos e metodológicos que nortearam todas as demais etapas do trabalho. Na seqüência, uma perspectiva histórica breve sobre a pesquisa agrícola em Santa Catarina é oferecida, buscando contextualizar a fase em que ela foi coordenada e executada pela EMPASC. Em 
seguida a trajetória organizacional da empresa é analisada, e empreende-se a busca de padrões estratégicos que caracterizaram sua atuação. Com base nessas análises, são apresentadas as conclusões sobre o caso estudado.

\section{Sobre os Aspectos Té́rico-Metodológicos}

Grande parte da literatura organizacional trata da questão da estratégia eminentemente sob o ponto de vista de empresas do setor privado (e.g., Miles e Snow, 1978; Porter, 1986; Day, 1989; Gracioso, 1990; Andrews, 1992; Hamel e Prahalad, 1994). Muito embora essa literatura traga contribuições relevantes, Pettigrew, Ferlie e McKee (1992) fazem a ressalva de que conceitos derivados do setor privado não podem ser mecanicamente transferidos para o setor público, uma vez que há muitas similaridades, mas há também diferenças entre os dois setores. Assim, como o artigo ora apresentado aborda uma organização do setor público, verifica-se que grande parte dessa bibliografia não se aplica em toda sua plenitude na análise da pesquisa realizada.

Ademais, muito do que se tem escrito sobre estratégia pressupõe sua conceituação como um conjunto de diretrizes conscientemente deliberadas que orientam as decisões organizacionais. Essa conceituação, chamada de planejamento estratégico, é representativa das escolas prescritivas do pensamento estratégico, que também não é apropriada para a discussão que se pretende com o presente trabalho. Dessa forma, após analisados conceitos sobre estratégia, optou-se por adotar apenas o referencial teórico de Mintzberg (1992) para esta pesquisa.

Mintzberg (1992) distingue cinco definições de estratégia: estratégia como plano, como blefe, como posição, como perspectiva e como padrão. Estratégia vista como plano é constituída de cursos de ação conscientemente pretendidos. Eles são elaborados antes das ações e desenvolvem-se consciente e propositadamente.

A segunda definição concebe estratégia como blefe (ploy), que são as ações realizadas no campo da competição, onde ameaças, jogadas e outras manipulações são empregadas para ganhar vantagem e desencorajar os competidores (Mintzberg, 1992).

O autor também explora a definição de estratégia como posição, que é a forma de colocar a organização no seu ambiente competitivo, de modo a garantir um domínio ou nicho no mercado. Nesse caso, a organização pode enfrentar, evitar ou subverter seus concorrentes. 
Na definição de estratégia como perspectiva, olha-se para dentro da organização; este conceito não reflete uma posição escolhida, mas uma visão de mundo coletiva da organização, que passa pelas noções de cultura, de ideologia e de personalidade da organização. Essa definição de estratégia é uma abstração, um conceito que existe apenas nas mentes das pessoas, mas é compartilhada pelos membros da organização, por meio de intenções e ações, consistindo numa mente coletiva (Mintzberg, 1992).

Finalmente, o autor apresenta o conceito de estratégia como padrão. O padrão é constituído pelo conjunto das estratégias realizadas (não só planos); podem ser ou não intencionadas e são observadas na consistência do comportamento organizacional ao longo do tempo; portanto o padrão é mais bem avaliado a partir de uma perspectiva longitudinal.

Dentro da definição de estratégia como um padrão, Mintzberg (1992) distingue ainda cinco tipos de estratégias. São as estratégias pretendidas, as deliberadas, as não realizadas, as emergentes e as realizadas. O padrão estratégico consiste no conjunto das estratégias pretendidas e deliberadas, somadas com as emergentes, ou seja, são as estratégias efetivamente realizadas.

\section{Figura 1: Tipos de Estratégia que Compõem o Padrão Estratégico}

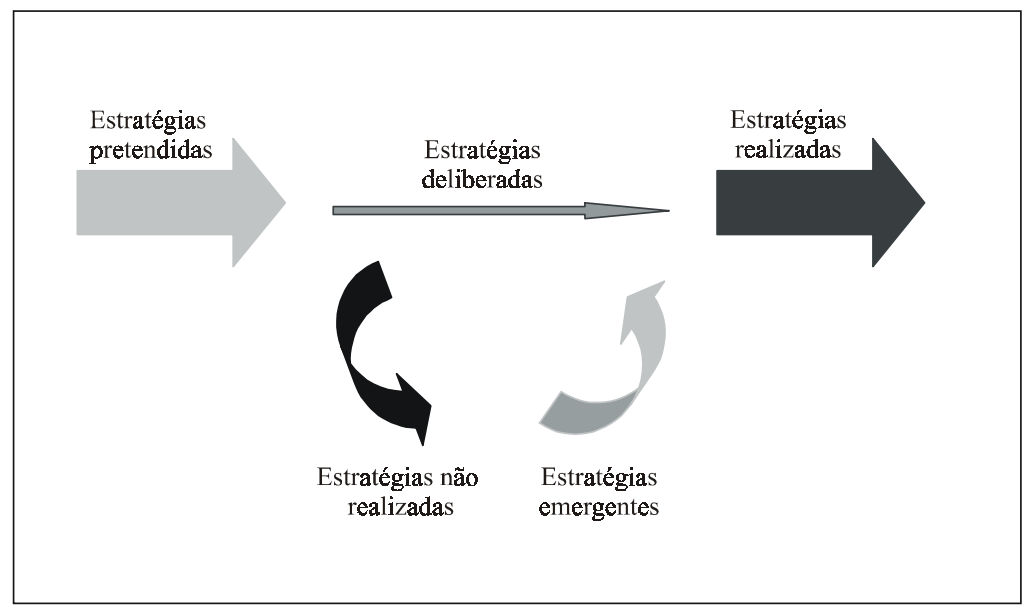

Fonte: Mintzberg (1992).

Nossa opção, diante dessas definições, é trabalhar nesse artigo com o conceito de estratégia como um padrão, uma vez que o padrão estratégico de uma organização revela tanto o que foi pretendido, deliberado e realizado, assim como aquilo que surgiu sem ser planejado, mas que também foi realizado. Assim, 
apenas um plano não produz um padrão, uma vez que algumas estratégias que são pretendidas não são realizadas; também um padrão necessariamente não resulta apenas de um plano, porque na sua consecução outras estratégias podem emergir.

Para analisar o padrão estratégico da EMPASC, optou-se pela pesquisa longitudinal (Pettigrew, Ferlie e McKee, 1992), partindo do pressuposto de que não é possível fazer um estudo dessa natureza, sem compreender o contexto histórico no qual os fatos ocorreram.

Cabe ressaltar que os dados coletados para a presente pesquisa são oriundos de fontes secundárias, ou seja, foram analisados documentos oficiais da organização e trabalhos já realizados por outros pesquisadores, interpretando-se de que forma eles revelam as estratégias de atuação da EMPASC nos seus quinze anos de existência.

\section{Perspectiva Histórica}

A história da EMPASC não pode ser contada apenas a partir de sua criação, na década de 70. Ela faz parte de um contexto maior, da história da pesquisa agrícola em Santa Catarina.

Começando em 1895, com uma iniciativa isolada, para trabalhos em uma só cultura, a pesquisa agrícola catarinense percorreu um longo trajeto até o momento presente, em que tem sob sua responsabilidade não só a geração de tecnologia em todos os produtos de importância econômica, social e ecológica para o Estado, como também a sua difusão.

Daquela época para cá, mudanças conjunturais ocasionaram rupturas que caracterizaram períodos ou fases da pesquisa agrícola no Estado (Santos, 1997b).

O primeiro período, de 1895 a 1911, constitui-se basicamente na trajetória da Estação Agronômica do Estado. Ela foi criada pelo Governo Estadual em Rio dos Cedros, naquela época município de Blumenau. As razões para a sua criação estavam ligadas aos problemas dos produtores de fumo da região, na condução de suas lavouras, no acondicionamento do fumo e na sua conservação para exportação (Santos, 1998).

Por vários problemas, como a falta de recursos financeiros e a inadequação de sua localização, a estação foi transferida para a capital do Estado, inicialmente, em 1904, para o Arraial do Estreito, e posteriormente, em 1907, para a região de 
Pedra Grande, hoje bairro da Agronômica (Santos, 1998). As atividades da Estação Agronômica se estenderam até 1911, se bem que já em decadência, até ser extinta em 1920.

O segundo período começa na década de 30 , com a estruturação de várias estações experimentais pelo Ministério da Agricultura, e se estende até a década de 50; foi uma fase em que o Ministério assumiu praticamente a condução de toda a pesquisa agrícola no Brasil, a partir de políticas e diretrizes agrícolas em nível nacional. Nessa fase, foram criadas três estações experimentais em Santa Catarina: a de Lages, em 1934, voltada exclusivamente para a área animal; a de Perdizes (atual município de Videira), em 1936, especialmente criada para pesquisar frutas de clima temperado, em particular a videira; a de Rio Caçador (atual município de Caçador), em 1937, para pesquisas na cultura do trigo. Ainda nessa fase, em 1943, o Ministério da Agricultura criou a Subestação de Enologia de Urussanga, no sul do Estado, para trabalhos com vitivinicultura (Santos, 1997b)

No início dos anos 60 observa-se o surgimento de um novo período, caracterizado pela tomada de posição do Governo Estadual, diante da predominância do Ministério da Agricultura, na condução da pesquisa local. Esta tomada de posição concretizou-se na organização de subestações de pesquisa em Rio do Sul e Jaguaruna. Marcou esse período, principalmente, a concepção e operação da Rede Experimental Catarinense, que consistiu em um acordo informal entre todas as estações de pesquisa para definir a programação técnica e a distribuição de recursos financeiros. Participavam da rede, ainda, a Associação de Crédito e Assistência Rural de Santa Catarina (ACARESC), os postos agropecuários do Ministério, colégios agrícolas, prefeituras, cooperativas e outras entidades (Santos, 1997b).

A partir de 1970, instaura-se um novo período na pesquisa agropecuária em Santa Catarina. Esse período teve início com a passagem de todas as estações experimentais pertencentes ao Ministério da Agricultura à jurisdição do Instituto de Pesquisas e Experimentação Agropecuária do Sul (IPEAS), em consonância com a política de descentralização adotada pelo Ministério.

Nessa época foi criada a Estação Experimental de São Joaquim, com pesquisas voltadas à área de fruticultura, especialmente a maçã. As atribuições das estações foram revistas e redimensionadas, até mesmo as da recém-criada Estação Experimental de Chapecó, posto agropecuário que funcionava desde 1948. Dessa forma, até 1975, a estrutura da pesquisa agrícola no Estado de Santa Catarina era composta por três estações pertencentes ao Governo do Estado: São Joaquim, Jaguaruna e Rio do Sul. Havia cinco estações vinculadas ao Ministério da Agricultura/IPEAS: Caçador, Videira, Lages, Urussanga e Chapecó. 
Outra fase se inicia com a criação da Empresa Catarinense de Pesquisa Agropecuária (EMPASC) em outubro de 1975. A EMPASC absorveu as estações ligadas ao Ministério da Agricultura, assim como as estações pertencentes ao Governo do Estado, com a competência de coordenar e executar a pesquisa agrícola estadual (Santos, 1997b). Após quinze anos de existência, a EMPASC foi extinta em 1991, como resultado de uma reforma administrativa do Governo Estadual, e concretizou-se na fusão das estruturas estaduais de pesquisa (EMPASC), extensão rural (ACARESC), extensão da pesca (ACARPESC) e extensão apícola (IASC) (Duarte et al., 1995).

Novo período delineia-se a partir desse evento. Com a fusão destas entidades, foi instituída a Empresa de Pesquisa Agropecuária e Extensão Rural de Santa Catarina S/A (EPAGRI). Essa fusão tinha por objetivos a racionalização de recursos e o "enxugamento da estrutura" do Governo do Estado (EPAGRI, 1993, p. 7).

O próximo item discutirá a fase escolhida para a análise neste estudo: o período EMPASC (1975-1990).

\section{EMPASC: IDENTIFICANDO UM PADRÃO}

Para compreender a trajetória da EMPASC, é importante mencionar o papel da Empresa Brasileira de Pesquisa Agropecuária (EMBRAPA), na sua implantação. A EMBRAPA foi criada em 1972, com o objetivo de implantar e coordenar o Sistema Nacional de Pesquisa Agropecuária (SNPA). Sua criação e a implantação do SNPA alteraram profundamente a organização da pesquisa agrícola no Brasil.

No que se refere à organização da pesquisa agrícola nos Estados, a criação da EMBRAPA também teve profundas repercussões. Foram criadas empresas congêneres em quase todos os Estados, seguindo as diretrizes e o modelo de atuação definidos por ela. Para alguns autores, essas mudanças representaram a possibilidade de estabelecer um modelo institucional de pesquisa "em condições de fazer face ao desafio da modernização da agropecuária brasileira" (Alves, 1980, p. 62) e com uma estrutura flexível de administração da pesquisa (Carvalho, 1992; Sousa, 1993). Para outros, elas representavam um meio de controle dos mecanismos de intervenção do Estado e de imposição de prioridades (Aguiar, 1986; Sobral, 1988). Para Santos (1989) a criação do SNPA foi uma evidência de que os Estados estavam perdendo o comando e a direção de suas respectivas políticas agrícolas, ficando o seu planejamento vinculado à estrutura do Governo Federal. 
Foi no âmbito dessa decisão de criação de empresas subordinadas ao SNPA que, a partir de então, foram implantadas empresas estaduais de pesquisa em diversos Estados, incluindo Santa Catarina.

A EMPASC foi criada como empresa pública, com personalidade jurídica de direito privado, vinculada à Secretaria Estadual de Agricultura e Abastecimento. Foi constituída sob a forma de sociedade por ações, sendo seus principais acionistas o Governo do Estado (60\% do capital) e a Empresa Brasileira de Pesquisa Agropecuária ( $40 \%$ do capital). A partir da sua implantação, foi delineada a nova estrutura da pesquisa agropecuária em Santa Catarina, com a fusão das estações ligadas ao Ministério da Agricultura e das estações pertencentes ao Governo do Estado.

A estrutura organizacional da EMPASC, na época de sua criação, era composta por Assembléia Geral, Conselho Técnico, Diretoria e Conselho Fiscal. Contava no nível de assessoria com uma Coordenação de Difusão de Tecnologia, uma Coordenação de Documentação e Informação, uma Coordenação de Planejamento, uma Auditoria Interna e uma Assessoria Jurídica; e no nível operacional com uma Diretoria Técnica e uma Diretoria Administrativa (EMPASC, 1976; EMPASC, 1977).

Nos anos que se sucederam, a EMPASC apresentou um padrão de crescimento paulatino de suas bases físicas, laboratórios, de seu quadro de pessoal, de suas atividades de pesquisa e difusão, de seus intercâmbios científicos e relacionamentos interinstitucionais.

Em relação aos seus recursos humanos, a EMPASC contou inicialmente com o pessoal que atuava nas Estações Experimentais do Ministério da Agricultura, da EMBRAPA e do Governo do Estado e iniciou uma política de contratação de pesquisadores e outros profissionais, atingindo já ao final de 1976 um total de 327 pessoas entre pesquisadores, pessoal de apoio e pessoal administrativo (EMPASC, 1977).

No final do período analisado, em dezembro de 1990, a EMPASC contava com 810 empregados, sendo 249 técnicos de nível superior, dos quais 205 eram pesquisadores, 44 pertencentes às áreas de suporte à pesquisa e 561 de outros níveis (Santos, 1993).

Houve, no decorrer dos seus quinze anos de existência, a preocupação de capacitar continuamente seu pessoal técnico, o que pode ser visualizado na Tabela 1 , a seguir. 
Tabela 1: Evolução do Quadro de Pesquisadores da EMPASC, nos Anos de 1975/80/85/90

\begin{tabular}{c|c|cc|cc}
\hline Pe ríodo & Total & \multicolumn{2}{c|}{ Com Graduação } & \multicolumn{2}{c}{ Com Pós-Graduação } \\
& & $\mathrm{n}^{\mathrm{O}}$ & $\mathbf{0}$ & $\mathrm{n}^{\mathrm{O}}$ & $\%$ \\
\hline 29.10 .75 & 14 & 10 & 71 & 04 & 29 \\
31.12 .80 & 104 & 47 & 45 & 43 & 48 \\
31.12 .85 & 175 & 49 & 28 & 126 & 72 \\
31.12 .90 & 199 & 44 & 22 & 155 & 78 \\
\hline
\end{tabular}

Fonte: adaptado de Santos (1993, p. 86).

Obs.: incluídos os pesquisadores de outros órgãos trabalhando na EMPASC.

A programação de pesquisa da EMPASC foi definida, pela primeira vez, para o ano agrícola 1975/76. Constou de 11 programas, nos quais se deu início aos trabalhos de pesquisa, detalhando seus projetos e experimentos componentes (EMPASC, 1975). A partir desse primeiro ano agrícola, sucederam-se, a cada ano, programações de pesquisa aprovadas e divulgadas no documento anual denominado Plano Estadual de Pesquisa Agropecuária, até o ano agrícola 1987/88. A partir daí, ocorreu uma mudança de periodização, passando os referentes a 1989 e 1990, para ano civil (Santos, 1993).

Quantitativamente, a evolução da programação teve um aumento progressivo no número de projetos e experimentos até os últimos anos, quando se observa uma tendência à redução, conforme consta na Tabela 2 , apresentada na seqüência.

No que diz respeito às alterações qualitativas, em 1975, a programação de pesquisa da EMPASC era composta pelos seguintes programas: arroz; bovinos; feijão; fruticultura de clima temperado; maçã; mandioca; pêssego; milho; soja; trigo; sorgo.

Dados da pesquisa de Santos (1993) mostram que, até 1990, quando foi extinta, houve alterações muito grandes na programação da EMPASC, na qual foram acrescentados alguns programas, como cevada, alho, cebola, aquicultura; alguns programas tiveram seus enfoques modificados, como as pesquisas com arroz que, a partir de 1987, passaram a compor o programa de arroz irrigado; outros ainda foram extintos, como o programa de sistemas produtivos para pequenas propriedades. 
Tabela 2: Evolução Quantitativa dos Programas, Projetos e Experimentos na EMPASC no Período de 1975 a 1990

\begin{tabular}{c|c|c|c}
\hline ANO & PROGRAMAS & PROJETOS & EXPERIMENTOS \\
\hline $1975 / 76$ & 11 & 79 & 232 \\
$1976 / 77$ & 13 & 89 & 247 \\
$1977 / 78$ & 14 & 92 & 239 \\
$1978 / 79$ & 13 & 82 & 245 \\
$1979 / 80$ & 11 & 73 & 230 \\
$1980 / 81$ & 16 & 87 & 276 \\
$1981 / 82$ & 18 & 101 & 287 \\
$1982 / 83$ & 17 & 129 & 325 \\
$1983 / 84$ & 18 & 147 & 377 \\
$1984 / 85$ & 20 & 164 & 433 \\
$1985 / 86$ & 24 & 212 & 499 \\
$1986 / 87$ & 25 & 242 & 530 \\
$1987 / 88$ & 24 & 235 & 538 \\
1989 & 22 & 229 & 549 \\
1990 & 20 & 223 & 483 \\
\hline
\end{tabular}

Fonte: Santos (1993, p. 89).

A análise realizada pela autora (Santos, 1993) mostra que as mudanças na programação de pesquisa da EMPASC se deveram principalmente a alterações na participação das fontes de recursos, ou seja, a forma pela qual os recursos ingressaram na instituição: alocação institucional ou vinculada a projetos; sua origem: setor público ou privado; a estratégia de alocação das fontes: determinando ou não a abrangência de projetos, vetando ou não a aplicação a determinados elementos de despesa, vinculando ou não a concessão de recursos a determinada linha de pesquisa e cultura; conseqüentemente, a alteração da composição dessas fontes no orçamento anual da empresa constituíram fatores que condicionaram e direcionaram a definição dos objetivos operacionais da EMPASC, ou seja, a programação de pesquisa.

Portanto houve uma estratégia de diversificação das culturas pesquisadas, condicionada, em grande parte, pela escassez ou abundância de recursos financeiros para a realização das pesquisas. 
Em relação aos intercâmbios científicos e relacionamentos institucionais, no tempo da sua criação, a EMPASC teve a preocupação não apenas com a manutenção de acordos e convênios anteriormente firmados, como buscou novas oportunidades de realização de pesquisas em cooperação com outros órgãos (EMPASC, 1978). Como exemplo, podem-se citar, entre outros, convênios com o Governo do Japão (Agência de Cooperação Internacional do Japão - JICA); com o Governo da Alemanha (Sociedade Alemã de Cooperação Técnica - GTZ); com a Rutgers University de New Jersey, EUA (EMPASC, 1977).

Ao longo dos anos, esses relacionamentos foram sendo concretizados em número cada vez maior, ao ponto de a EMPASC manter convênios com diversas instituições nacionais e internacionais, públicas ou privadas, universidades, associações de produtores, cooperativas, prefeituras, entre outras, no final de 1990 (EMPASC, 1991).

Os dados anteriormente apresentados reforçam a idéia de que houve um padrão de crescimento, concretizando-se também numa expansão geográfica. Essa expansão geográfica pode ser constatada pela criação das estações experimentais de Campos Novos, Jaguaruna, Ituporanga, Canoinhas (em implantação no último ano), bem como da unidade demonstrativa de Rancho Queimado e do Campo Experimental de Piscicultura em Camboriú (vide Figura 2).

\section{Figura 2: Distribuição da Pesquisa Agrícola em Santa Catarina em 1990}

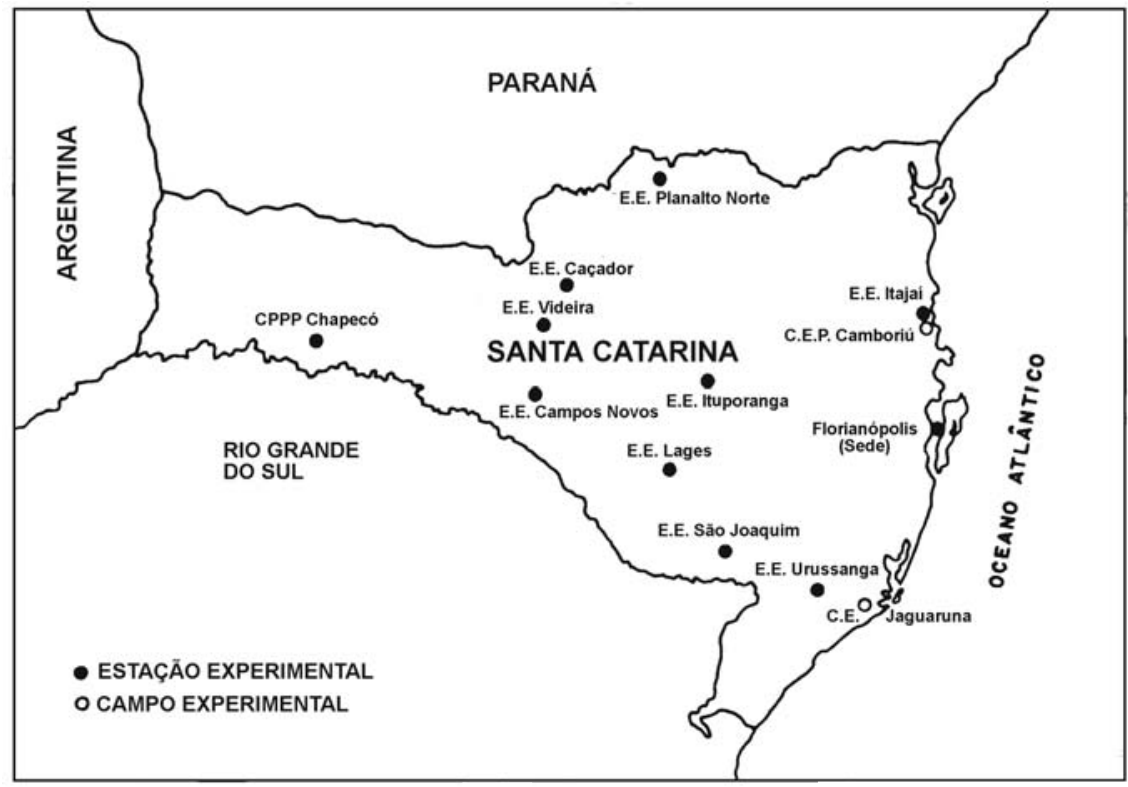

Fonte: EMPASC (1991). 


\section{Destacando Estratégias}

O item anterior teve a intenção de apresentar um breve perfil da EMPASC em seu período de existência, mostrando que a organização apresentou um padrão de constante crescimento, explicitado, entre outros indicadores, no aumento e capacitação de seu quadro de pessoal, nas mudanças quantitativas e qualitativas de sua programação de pesquisa e na contínua expansão geográfica realizada.

A partir de agora, faremos uma descrição mais detalhada de três momentos vividos pela organização. Esses momentos foram escolhidos, porque fornecem subsídios para a análise de três importantes estratégias que convergiram para compor o padrão de crescimento da EMPASC em seus quinze anos de existência. Os três eventos aqui descritos mostram como um conjunto de estratégias pretendidas, deliberadas, não realizadas, emergentes e realizadas compõe o padrão estratégico de uma organização (Mintzberg, 1992). Assim, a dependência em relação à EMBRAPA, a articulação com o Governo do Estado e a negociação com a iniciativa privada contribuíram para compor o padrão de crescimento da EMPASC, de 1975 a 1990.

\section{A Dependência em Relação à EMBRAPA}

A EMPASC, apesar de ter sido criada como empresa pública em nível estadual, esteve desde o início estreitamente ligada ao SNPA, por meio do convênio firmado com a EMBRAPA em 27 de outubro de 1976. Nesse convênio foram definidas as atividades de ensino, pesquisa e difusão, e a delegação da responsabilidade da pesquisa agropecuária em Santa Catarina, dentro dos moldes do Sistema Nacional. Foram acertadas nessa época, ainda, as modalidades da cooperação técnica, material e financeira entre as duas entidades (Santos, 1993). Esse acordo inseriu a nova empresa e sua programação nas políticas de desenvolvimento institucional, treinamento técnico, intercâmbio científico e outras, coordenadas pelo SNPA, e delimitou aspectos relevantes no seu modus operandi, o que definiu o padrão de atuação da EMPASC, por muitos anos.

Para efeito desta análise, cabe destacar que o convênio EMBRAPA-EMPASC determinou aspectos singulares no relacionamento entre as empresas. Um deles era assegurar que a EMBRAPA pudesse designar cargos de direção da EMPASC (Santos, 1993). Assim, a prerrogativa da EMBRAPA de indicar o diretor técnico da EMPASC refletia, de certa forma, uma estratégia da EMBRAPA para garantir seu status de coordenadora e seu espaço na definição da programação de pesquisa. 
A análise do vínculo EMBRAPA-EMPASC, embora tenha significado importantes avanços para a empresa catarinense, por se integrar a um sistema nacional com forte massa crítica e abundância de recursos, também evidencia o que Aguiar (1986) qualifica como calibração científica. Essa calibração ocorreu, por um lado, pelas condições impostas pela EMBRAPA à EMPASC, respaldada pela sua função de coordenadora do SNPA, evidenciando uma "subordinação política das empresas estaduais a uma instituição federal" (Aguiar, 1986, p. 50); por outro lado, implicou a aceitação pela EMPASC das condições impostas, por convênio, pela EMBRAPA, na sua implantação. O convênio firmado garantia que a EMPASC se pautaria por diretrizes de ação, critérios de escolha de dirigentes, definição de metodologias de trabalho etc., impostos pela EMBRAPA, como condição para obter apoio financeiro. Nesse período, os projetos eram propostos aos Centros Nacionais de Pesquisa, sendo posteriormente encaminhados à própria sede da EMBRAPA, para sua aprovação. Uma vez aprovados, garantia-se a liberação de recursos federais, dando início à fase de execução da programação de pesquisa (EMPASC, 1976).

Na visão de Rosseto (1986), o papel de repassador de recursos do Programa Nacional, possibilitava, mediante recursos de valor não muito significativo, a "expropriação de idéias, metodologias e informações", sob o nome de sistema "cooperativo" (Rosseto, 1986, p. 68). Os fatos, até certo ponto, parecem comprovar as observações desse autor, uma vez que os resultados dos projetos e experimentos vinculados ao Programa Nacional eram enviados anualmente à EMBRAPA sob a forma de relatórios técnicos, e publicados a cada ano, sob o título de Tecnologias Geradas pelo Sistema EMBRAPA.

Verifica-se que a dependência da EMPASC em relação à EMBRAPA perdurou até por volta de 1985 , quando a redução dos recursos alocados aos projetos da EMPASC tornou praticamente irrelevante a participação da EMBRAPA como fonte financiadora dos projetos. Nessa época, esboçou-se, por parte do corpo técnico da EMPASC, uma tentativa mais enfática de questionamento da EMBRAPA sobre a redução de sua participação no orçamento da EMPASC, e até cogitou-se, em reuniões do Sistema Nacional, a possibilidade de que os projetos da EMPASC fossem retirados da programação do Sistema Nacional. Passou a haver então, um novo posicionamento, um pouco mais crítico, mesmo em relação ao papel extremamente centralizador da EMBRAPA, em decorrência do qual apenas os projetos com reais possibilidades de financiamento passaram a ser submetidos à sua aprovação (Santos, 1993).

O padrão existente nos dez primeiros anos de vida da EMPASC, de uma submissão quase completa ao poder centralizador do Sistema Nacional, foi pouco a pouco perdendo força, à medida que a EMBRAPA não tinha mais recursos para 
financiar pesquisas no Estado, e que a própria EMPASC foi adentrando em áreas que o Sistema Nacional não considerava prioritárias ou para as quais não possuía massa crítica, como os programas de pesquisa em sistemas de produção para pequenas propriedades, mecanização agrícola ou em simulídeos.

Analisando essa fase com base no modelo de Mintzberg (1992), pode-se afirmar que a relação de dependência com o SNPA foi uma estratégia deliberada e realizada durante muitos anos. Foram as estratégias emergentes, ou seja, a escassez de recursos da fonte EMBRAPA e a entrada da EMPASC em áreas específicas, que condicionaram a não prosseguir nessa estratégia por parte da organização catarinense.

Apesar disso, o relacionamento com a EMBRAPA existiu até o final, não mais em bases de dependência financeira, mas caracterizado pela condução de trabalhos conjuntos, intercâmbio de idéias e troca de materiais, como mudas, sementes etc.

\section{A Articulação com o Governo do Estado}

O Estado de Santa Catarina tem como característica a pequena propriedade rural, de exploração familiar. Com o objetivo de assegurar o aumento da capacidade produtiva dessas pequenas propriedades, a EMPASC instituiu no ano agrícola 1983/84 o Plano Integrado de Pesquisa em Sistemas Diversificados de Produção para Pequenas Propriedades (PSDPP).

Partindo do pressuposto de que nas pequenas propriedades agrícolas coexistem diferentes atividades de produção (culturas anuais, plantas perenes, criação de animais), esse plano propunha-se a adotar a metodologia de estudo e análise de sistemas (enfoque sistêmico). Esse trabalho era realizado juntamente com a extensão rural (ACARESC) e o produtor, partindo da abrangência da propriedade, do produtor e da região. Para tanto, a Estação Experimental de Chapecó foi transformada no Centro de Pesquisa para a Pequena Propriedade (CPPP); o município de Nova Erechim foi escolhido como local para o diagnóstico-piloto. Esse fato foi considerado, institucionalmente, o evento mais importante ocorrido na EMPASC em 1983 (EMPASC, 1984).

O estilo arrojado da EMPASC com esse empreendimento fica evidenciado no fato de que o CPPP foi a primeira unidade de pesquisa do país criada com o fim específico de estudar a pequena propriedade (EMPASC, 1986).

Cabe destacar que, em 1982, com o projeto desse plano já elaborado e com a proximidade das eleições estaduais para governador, as quais o candidato do Governo apresentava como plataforma política a prioridade aos pequenos, a idéia do CPPP foi absorvida por esse candidato e transformada em compromisso 
de campanha, e mais tarde, após o resultado favorável das urnas, em parte integrante do plano de governo. Com essa informação em mãos, a estratégia da EMPASC foi aguardar a posse do novo governador para lançar o programa, na expectativa de que, com tão forte compatibilidade entre os propósitos do PSDPP e as prioridades declaradas pelo Governo, fosse possível obter recursos mais abundantes, que possibilitassem a sua plena implantação (Santos, 1993).

A estratégia de cooptação de uma liderança, que detinha o poder de determinar ou exercer influência sobre a política da organização, é evidenciada em documentos oficiais da EMPASC, que destacavam o "apoio irrestrito do Governo de Santa Catarina na pessoa do governador" (EMPASC, 1985, p. 5) à criação do CPPP e a "perfeita consonância [dos objetivos do centro] com o estabelecido na 'Carta dos Catarinenses' [documento do plano de governo], de 'prioridade aos pequenos', marco norteador do Governo” (EMPASC, 1984, p. 5).

Essa estratégia, entretanto, não surtiu o efeito desejado, uma vez que o apoio do Governo, já empossado, tanto em temos financeiros quanto em prestígio, restringiu-se à presença do novo governador na inauguração do centro, à citação da linha de pesquisa nos discursos e relatórios oficiais e aos poucos recursos alocados ao programa (Santos, 1993).

Além disso, uma série de fatos contribuiu para que o PSDPP, a partir de 1986, fosse pouco a pouco sendo alterado em sua concepção original. Essas alterações foram ocorrendo com relação ao projeto, à abordagem, à equipe interdisciplinar, descaracterizando a proposta inicial de pesquisa, até ser completamente extinto da programação de pesquisa em 1988. Somado às dificuldades de conseguir recursos (junto ao Governo do Estado e da Financiadora de Estudos e Projetos FINEP), houve ainda interferência de diversos interesses político-partidários e de coalizões internas e externas, com objetivos diferentes daqueles definidos para o programa (Santos, 1993).

À luz do modelo de Mintzberg (1992) essa parece ser uma fase em que, aproveitando-se de um momento político propício, a EMPASC planejou e executou sua estratégia de atuação; entretanto as resistências e dificuldades que emergiram do ambiente externo e interno levaram o PSDPP a se transformar numa estratégia não realizada.

\section{Negociação com a Iniciativa Privada}

Os últimos anos de existência da EMPASC foram caracterizados pela escassez de recursos para o financiamento da pesquisa, uma vez que os montantes repassados pelas fontes financiadoras tradicionais e pelo Governo eram insufici- 
entes para a manutenção da programação de pesquisa. Nessa época, os convênios firmados com a iniciativa privada foram um meio encontrado para contornar essa situação. Dentro dessa diretriz, foram estabelecidos convênios com firmas particulares, visando a desenvolver tecnologias nas culturas da batata, da maçã, do arroz irrigado, da cebola, do feijão, da banana, da mandioca e do milho (EMPASC, 1989, 1990, 1991). Essa aproximação com o setor privado resultou no incremento das receitas de custeio e até mesmo intensificou o relacionamento da EMPASC com o setor produtivo. Como decorrência dessa estratégia, começouse a observar alterações na forma como se dava a definição dos objetivos organizacionais, ou seja, a programação de pesquisa.

O caso da maçã é revelador ao mostrar até que ponto essa participação da iniciativa privada teve o poder de alterar a programação de pesquisa da EMPASC. Dados da pesquisa realizada por Santos (1993) revelam que, em 1990, um ano que contou com 11 projetos novos no Programa Maçã, 7 projetos foram financiados pela Associação dos Fruticultores da Região de Fraiburgo (AFRF); ou seja, apenas 4 projetos não foram financiados pela AFRF.

A análise revela que tal situação pode ser vista de duas maneiras: ou evidencia uma coincidência entre as novas propostas de pesquisa da EMPASC e da AFRF, ou pode indicar que os interesses da AFRF, reforçados pela disponibilidade de recursos, estariam efetivamente interferindo na definição da programação de pesquisa.

$\mathrm{Na}$ interpretação do relacionamento entre o Programa Maçã da EMPASC e a AFRF fica evidenciado que, se este fato tem um lado positivo, representado pelo ingresso de recursos e pela participação do setor produtivo na definição da programação, tem por outro lado, a participação de apenas um segmento do setor produtivo, o dos grandes fruticultores. Ademais, o relacionamento que se estabelece entre os institutos de pesquisa e as empresas financiadoras pode induzir a que os primeiros atuem como departamentos de $\mathrm{P} \& \mathrm{D}$ do setor privado, que muitas vezes não têm estrutura ou recursos para tal. Isto também pode levar ao que Oszlak (1982, p. 45) chama de "deslocamento de objetivos", quando o instituto de pesquisa, dependente de seus financiadores, se adapta aos interesses dessas entidades, ou até mesmo à "feudalização" da pesquisa, na qual o relacionamento se converte "em uma virtual posse dos órgãos por sua clientela". Com referência a esse fato, cabe citar Morel (1978), que afirma que não é em nome de uma ciência neutra que os cientistas recebem ofertas de financiamentos para projetos. Sendin (1982) alerta para o risco de que a concessão de recursos para pesquisa e viagens de estudo seja uma forma de cooptação e direcionamento das pesquisas dos cientistas. 
Santos (1997a) ainda questiona o modelo de alocação de recursos utilizado no caso maçã, uma vez que a AFRF não alocava os recursos à EMPASC, institucionalmente. A concessão de recursos era baseada em acordos informais, concretizando-se por meio da abertura de créditos junto a empresas fornecedoras de materiais e insumos, demandados pelos projetos da maçã, além do custeio de viagens, compra de material bibliográfico etc. A explicação obtida para justificar esse tipo de financiamento parece indicar a incerteza de que as prioridades da AFRF fossem realmente contempladas, se os recursos fossem diluídos na programação. $\mathrm{O}$ temor demonstrado pareceu ter fundamento, uma vez que, do ponto de vista do orçamento estadual, os recursos captados de outras fontes poderiam provocar redução no volume de recursos alocados pela fonte Governo do Estado; ou seja, na visão da AFRF, os recursos ficariam do mesmo tamanho.

O que transparece é a busca da garantia de que as prioridades da AFRF, à qual estão filiados os grandes produtores, fossem pesquisadas. Sob esse aspecto, a AFRF pode ser vista como um forte grupo externo, ou seja, uma coalizão externa que influencia o estabelecimento dos objetivos da organização, uma vez que o simples fato de os pesquisadores saberem, por um lado, que existia uma disponibilidade de recursos e, por outro, quais eram as áreas de interesse da associação, certamente provocou um direcionamento, ainda que não explícito, da programação da maçã para os interesses dos grandes produtores (Santos, 1993).

Gomensoro (1985) explica esse tipo de influência, lembrando que, ainda que a entidade de pesquisa deva definir sua programação a partir de necessidades sociais, se sua sobrevivência depender da obtenção de recursos, acabará sendo levada a sair em busca desses recursos. Entre os setores interessados nos resultados da pesquisa, os segmentos pequenos, esparsos, pouco dinâmicos, com certeza não têm condições de atender às necessidades de recursos dos centros de pesquisa, os quais acabam voltando-se para a captação junto a empresas/grupos dinâmicos, fortes e em expansão, exemplificados, nesse caso, pela Associação dos Fruticultores.

É importante ressaltar que este caso específico do Programa Maçã revelou uma tendência da EMPASC, nos seus últimos anos de existência, a sofrer, de forma implícita ou explícita, a influência dos interesses da iniciativa privada em sua programação de pesquisa. Essa estratégia não foi planejada nem formalizada em documentos, mas o ambiente externo, com suas contingências e necessidades emergentes, fez com que a EMPASC buscasse as fontes de recursos da iniciativa privada para dar continuidade aos seus objetivos organizacionais. Nesse caso, foram as estratégias emergentes que condicionaram a consecução das estratégias realizadas (Mintzberg, 1992) da EMPASC, no início dos anos 90. 


\section{CONCLUSÓES}

Ao fazer todo o levantamento da história da pesquisa agrícola em Santa Catarina, a opção de estudar em profundidade a fase EMPASC (1975-1990) deveuse ao fato de que esse período abrangeu toda a vida da empresa que por mais tempo respondeu pela pesquisa agrícola no Estado, e de existirem dados organizados e disponíveis para consulta.

A análise dos quinze anos de vida da EMPASC revelou um padrão de crescimento observado na progressiva expansão geográfica, bem como na crescente diversificação de produtos pesquisados e de serviços prestados pela organização.

Neste trabalho, foram analisadas algumas das estratégias que se destacaram na história da EMPASC, reforçando o seu padrão de crescimento e representando momentos relevantes na trajetória da pesquisa agrícola em Santa Catarina.

A primeira estratégia analisada caracterizou-se pela adequação da EMPASC às diretrizes, procedimentos e exigências da EMBRAPA, tanto no que diz respeito à programação de pesquisa quanto à organização da estrutura formal da empresa, durante praticamente dez anos. Esse relacionamento foi enfraquecendo com o tempo, quando o papel coordenador da EMBRAPA se foi tornando menos determinante para os objetivos da EMPASC.

A segunda estratégia analisada constituiu a tentativa da EMPASC de aproveitar a identidade entre uma proposta técnica - implantar um programa e um centro de pesquisa voltados ao pequeno produtor rural - e a plataforma eleitoral de um candidato ao Governo do Estado - prioridade aos pequenos. Essa convergência de fato aconteceu, no momento de implantação do plano de Governo, porém não teve continuidade de modo a garantir a implementação plena do projeto e sua consolidação.

A terceira estratégia analisada se evidenciou apenas nos últimos anos de atuação da EMPASC, podendo ser considerada como uma tendência a um relacionamento mais estreito entre a pesquisa e o setor privado, partindo do pressuposto de que a transferência de tecnologia pode resultar em captação de recursos.

Essas três estratégias parecem demonstrar o modo como a EMPASC tentou ajustar-se ao ambiente: a primeira, ao ambiente científico; a segunda, ao ambiente político; e a terceira, ao mercado, neste caso representado pelos usuários da tecnologia. Esse ajuste aos diversos ambientes caracteriza o que Miles e Snow (1978) chamam de adaptação organizacional. Resguardadas as devidas proporções, o relacionamento da EMPASC com a EMBRAPA e com a iniciativa priva- 
da parece demonstrar o modelo de seleção natural, no qual o ambiente define o destino das organizações. Por outro lado, a tentativa da EMPASC de decretar seu ambiente (Weick apud Miles e Snow, 1978), pode ser visualizada na sua intenção de cooptar forças políticas para a consecução de seus objetivos.

Uma análise à luz de Mintzberg (1992) demonstra que o padrão estratégico observado resultou de uma combinação de estratégias pretendidas, deliberadas e emergentes. A atuação conjunta com a EMBRAPA foi deliberada em documentos formais e convênios, e realizada por um longo período. $\mathrm{O}$ relacionamento com a iniciativa privada emergiu num momento de crise sem uma prévia intenção institucional, mas que evidenciava a tendência de constituir-se num padrão. Finalmente, a estratégia pretendida de implantar uma nova linha de pesquisa, com o comprometimento do Governo do Estado, acabou não sendo realizada, por uma série de contingências e condições emergentes.

Após quinze anos de existência, a EMPASC foi extinta por ato governamental, que determinou sua fusão com outras empresas estaduais, dando origem à EPAGRI. Esse evento final na história da EMPASC, numa análise preliminar, não parece condizente com as estratégias da organização analisadas neste artigo, porquanto, do ponto de vista organizacional, parecia que a EMPASC estava numa fase de plena consolidação de suas atividades, ou seja, nada indicava que ela estivesse prestes a se extinguir, apesar das crescentes dificuldades financeiras que se apresentavam na sua manutenção.

Por outro lado, evidencia-se uma consistência entre esse evento e a história da pesquisa agrícola em Santa Catarina, quando observada de uma perspectiva temporal mais ampla. Isso pode ser constatado na análise de sua trajetória, desde o final do século passado até o momento, a qual revela sucessivas descontinuidades, ilustradas pelas extinções, fusões, transferências e outros processos pelas quais passaram, diversas vezes, as entidades responsáveis pela pesquisa agrícola no Estado. Tal análise sugere que a pesquisa agrícola, institucionalizada como parte do setor público, deve ser entendida a partir de um contexto macro, que extrapola a perspectiva organizacional de análise, e a coloca como parte de uma arena política e econômica, na qual as estratégias e os objetivos das entidades estão submetidos a uma racionalidade que leva em conta tanto interesses de grupos quanto as decorrências da globalização da economia e da abertura dos mercados. 


\section{ReferênCias BiblográficAs}

AGUIAR, R. C.

Abrindo o pacote tecnológico :

Estado e pesquisa agropecuária no Brasil. São Paulo : Pólis, 1986.

ALVES, E. R. DE A.

$O$ modelo institucional da EMBRAPA. In: ALVES, E.; PASTORE, J.; PASTORE, A. C. Coletânea de trabalhos sobre a EMBRAPA. Brasília : EMBRAPA, 1980. documento 1.

ANDREWS, K. R.

The concept of corporate strategy. In: MINTZBERG, H.; QUINN, J. B. The strategy process : concepts and contexts. Englewood Cliffs, NJ : PrenticeHall, 1992. p. 44-51.

CARVALHO, J. C. M. DE.

$O$ desenvolvimento da agropecuária brasileira : da agricultura escravista ao sistema agroindustrial. Brasília : EMBRAPASPI, 1992.

DAY, G. S.

Deciding how to compete. Planning Review, p. 18-23, Sept./Oct. 1989.

DUARTE, C. M. L. et al.

Cem anos de pesquisa agrope- cuária em Santa Catarina 1895 - 1995. Florianópolis : EPAGRI, 1995.

\section{EMPASC.}

Plano anual de pesquisa agropecuária : ano agrícola 1975/76. Florianópolis, 1975.

Boletim de divulgação. Florianópolis, 1976.

Relatório anual 1976. Florianópolis, 1977.

Relatório ano 2. Florianópolis, 1978.

Relatório ano 8. Florianópolis, 1984.

Relatório ano 9. Florianópolis, 1985.

Relatório ano 10. Florianópolis, 1986.

Relatório ano 13. Florianópolis, 1989.

Relatório ano 14. Florianópolis, 1990.

Relatório ano 15. Florianópolis, 1991. 
EPAGRI.

Relatório EPAGRI ano 1. Florianópolis, 1993.

GOMENSORO, S. C. M. DE.

De quê, além de marketing, precisam as boas pesquisas tecnológicas do Governo? Ciência e Cultura, v. 37, n. 10, p. 16411643, out. 1985.

GRACIOSO, F.

Planejamento estratégico orientado para o mercado. 2. ed. São Paulo : Atlas, 1990.

HAMEL, G.;

PRAHALAD, C. K.

Strategic intent. In: Global strategies : insights from the world's leading thinkers. Boston, MA : The Harvard Business Review Books Series, 1994. p. 03-28.

MILES, R. E.;

SNOW, C. C.

Organizational strategy, structure and process. New York : McGraw-Hill, 1978.

MINTZBERG, $\mathrm{H}$.

Five P's for strategy. In: MINTZBERG, H.; QUINN, J. B. The strategy process. Englewood Cliffs, NJ : PrenticeHall, 1992. p. 12-19.
MOREL, R.

A SBPC e a função social (e política) do cientista. Cadernos de Tecnologia e Ciência, v. 1, n. 3, out./nov. 1978.

OSZLAK, O.

Políticas públicas e regimes políticos : reflexões a partir de algumas experiências latino-americanas. Revista de Administração Pública, v. 16, n. 1, p. 1670, jan./mar. 1982.

PETTIGREW, A. M.;

FERLIE, E.;

MCKEE, L.

Shaping strategic change : making change in large organizations - the case of the National Health Service. London: Sage Publications, 1992.

PORTER, M.

Estratégia competitiva. Rio de Janeiro : Campus, 1986.

ROSSETO, C. J.

Modelos institucionais de pesquisa. In: EMPRESA DE PESQUISA AGROPECUÁRIA DE MINAS GERAIS. Simpósio : pesquisa agropecuária e desenvolvimento sócio-econômico. Belo Horizonte : EPAMIG, 1986. documento 28 . 
SANTOS, L. W. DOS.

Alocação de recursos e objetivos organizacionais : um estudo sobre a pesquisa agrícola em Santa Catarina. Florianópolis, 1993. Dissertação (Mestrado em Administração) - Curso de Pós-Graduação em Administração, Universidade Federal de Santa Catarina.

Financiamento de pesquisa pública pela iniciativa privada - a cadeia produtiva da maçã em Santa Catarina. In: VII SEMINARIO LATINOAMERICANO DE GESTIÓN TECNOLÓGICA ALTEC (1997 : Habana). Memorias... Mexico : UNAM, 1997a. p.69-82.

A pesquisa agrícola em Santa Catarina : uma visão histórica de sua organização. AGORA, v. 12, n. 26, p. 30-43, 1997 b.

Estação Agronômica e de Veterinária do Estado (1895 1920) : uma abordagem histórica sobre o início da pesquisa agrí- cola em Santa Catarina. Florianópolis : Editora da UFSC, 1998.

SANTOS, R. S.

Breves notas sobre a natureza da política agropecuária brasileira : do planejamento por produto ao planejamento global. Revista de Administração Pública, v. 23, n. 2, p. 39-53, abr. 1989.

SENDIN, P. V.

Financiamento da pesquisa agrícola. Revista de Administração, v. 17 , n. 1 , p. $85-94$, jan./mar. 1982.

SOBRAL, F. A. DA F.

Estado e pesquisa agrícola no Brasil. Cadernos de Difusão de Tecnologia, v. 5, n. 1/3, p. 119130, jan./dez. 1988.

SOUSA, I. S. F. DE.

A sociedade, o cientista e o problema de pesquisa : o caso do setor público agrícola brasileiro. Brasília: EMBRAPA-SPI, 1993. 